\title{
Crazy Rush for Powdery Tobacco (Sunkho) among Younger Women and girls in Petauke and Chipata districts- Zambia: Is it cultural recovery or birth of a new lifestyle?
}

\author{
Jordan Tembo ${ }^{1}$, Patricia Mambwe ${ }^{2}$ \\ ${ }^{1}$ Kalindawalo General Hospital, P.O.Box 560008, Petauke, Zambia \\ ${ }^{2}$ Department of Nursing, School of Health Sciences, Rusangu University, Monze, Zambia
}

\begin{abstract}
Sunkho (snuff) is a fine ground tobacco inhaled as dry powder or dipped in the lip/gum groove or cheek/gum vestibule for sucking as moist tobacco-mixture. In Zambia, culturally, sunkho was purely consumed by the elderly. In recent years however, sunkho has become very popular among younger women and girls. This study explored where users sourced sunkho, how they consumed sunkho and whether users were aware about health-related effects of sunkho. The study was conducted in Chipata and Petauke Districts of Zambia between March and June, 2021.A total of 25 user and non-user participants, broken down as 6 males and 19 females participated in the study. User participants were sampled through snowball sampling method. The study used an explorative research design with a qualitative approach. A single interview-per participant method was used for data collection. This study found that younger women dashed for sunkho to elevate their body temperature from ordinary-warm to unusualwarmer and for vaginal tightening so that a man enjoys memorable and satisfactory sexual pleasure. Some users consumed sunkho based on the underlying belief that sunkho helps to boost CD4 Count in HIV positive patients. This study also found that other younger female users consumed sunkho under the belief that it prevented them from acquiring COVID19 while others did so out of need for social conformity with the prevailing fashion. The study found low levels of awareness among participants on health-associated risks of sunkho. Since users are continuously inventing methods of consuming sunkho, exposing themselves further to tobacco-associated cancers, this study recommends that health workers conduct aggressive community sensitization campaigns on sunkho and other smokeless tobacco products on health. Institutions offering health-related training programmes to include the use of Smokeless tobacco in their curriculum as a new threat to the emergence of malignancies of unknown origin among users. Ministry of Education to take a critical step in creating awareness to all pupils and students on the dangers of using sunkho and other smokeless tobacco products.
\end{abstract}

Key words: sunkho, sex, consumption, tobacco

\section{INTRODUCTION}

$\mathrm{T}$ he use of fine dry to semi-moist ground tobacco (snuff) is an ancient social behaviour. Societies use local names to refer to ground powdery tobacco. In Britain and the United
States of America it is known as snuff. Swedes call it snus (Leon et al., 2016). Indians call it Bajjar (Das, 2018). In North Africa they call it neffa or nufha (International Agency for Research on Cancer, 2004). In Sudan and Chad it is called toombak (Hassanin \& Idris, 2017). Ghanaians and Nigerians call it Tawa and Taaba (Centers for Disease Control and Prevention, 2015). On the Eastern part of Africa, Tanzanians call it ugoro (2018 Tanzania Global Adult Tobacco Survey Country Report, 2020). The Zulu of South Africa call it Intsu. In Zambia it is popularly known by the Nyanja term sunkho and the Bemba term insunkho. Sunkho belongs to the category of Smoke Less Tobacco (SLT) products. The Physicians for a Smoke-Free Canada (PSFC)(2010), describe sunkho-snuff as finely ground tobacco that can be dry or moist. Dry snuff often comes in powder form and can be inhaled through the nose while moist snuff, also called "dip" or "pinch", is placed between the lip and gum and does not need to be chewed (PSFC, 2010). Smoke Less Tobacco products are consumed without burning. Scholars consider Smoke Less Tobacco to be any form of tobacco that is not smoked but is sniffed through the nose, sucked, chewed or dissolved in the mouth (CDC, 2019). Fine ground tobacco mixtures are inhaled into the nostrils or sucked. The World Health Organization (WHO) (2017) identify two types of sunkho- namely dry and moist snuff. Dry snuff is powdered tobacco that is inhaled through the nose and absorbed through the nasal mucosa or taken orally. Moist snuff is ground tobacco held and sucked. This snuff is held in the mouth between the cheek/lip and gum (WHO, 2017).

Sunkho and other smokeless tobacco products are consumed by 356 million people worldwide (Sinha et al., 2018). According to the World Health Organization (2017), the consumption of sunkho has a long history even as early as before Christopher Columbus' voyage to the Americas with natives of South America being the first people known to use it. As colonizing European nations invaded and colonized the "New World,"- South America, explorers took note of the strange practice and brought knowledge of snuffing tobacco back to Europe (Mcglyn 2019:1). Sunkho has been used in 
many cultures for medical treatment, prevention of fatigue and hunger on long distance treks, and various rituals and ceremonial uses (Sand et al., 2014). Recent studies show that the use of sunkho was becoming popular especially in low-and middle-income countries. In these countries, considerable proportions of women, including those of reproductive age chew, dip or sniff tobacco (Sieminska \& Jassem, 2014). While the consumption of sunkho by women is global, the World Health Organization (WHO, 2017) estimates that in Africa alone there are over 13 million women using sunkho and other smokeless tobacco products. Earlier research found a higher prevalence in the use of sunkho among older women (Bauman, et al.,1989); Giovino, 2002). Recent studies however, reveal that daily use of sunkho has increased primarily among younger women. Belief that consumption of unburned tobacco products obviously 'eliminates the danger of direct exposure of toxic combustion compounds to the lung and other tissues of the user and of the people around' (European Union 2008: 14) has popularised the use of sunkho. Meanwhile, the prevalence rate in the use of sunkho and other smokeless tobacco products among women was higher in South-east Asia and Sub-Saharan Africa (WHO, 2017). The prevalence rate of consuming sunkho was said to be highest in Lesotho, Madagascar, Mozambique, Namibia and Zambia (Pampel, 2008).

Early studies show that use of sunkho was prevalent in rural areas among older women. In recent years however, girls and younger women are using sunkho. Høstmark et al. (2017) found that 1 out of 6 women aged 16-34years used sunkho daily in 2016. The popularity of sunkho has also come with a variety of ways in which it is consumed. Use of sunkho has been speculated on the grounds that it raises the woman's temperature and improves sexual performance by making the vagina dry. It is also speculated that sunkho tightens the user's vagina into the coveted "ideal" vagina: a youthful, tight, rounded vulva, with labia majora enclosing the labia minora and clitoris (Braun, 2005). Across cultures a tight vagina is desirable, while a 'loose' vagina is undesirable (Braun \& Kitzinger, 2001).) Commercial Sex Workers mindful of male customers' uppermost desire from them- a tight vagina- are forced to use cultural concoctions to ensure the vagina closed naturally (Sarmin et al., 2018). In Africa, a study by Ndinda et al. (2011) found that it was a common practice among the Zulu women of South Africa to insert sunkho in the vagina, to achieve a 'tight' vagina for the purpose of enhancing sexual pleasure for the man.

In Zambia, sunkho has attracted media attention. Print and non print media carry overwhelming stories about the growing trend of younger women and girls in Zambia resorting to using sunkho. Mwitwa (2018) in her article titled plying bedroom duties reports that sunkho, the traditionally widely known form of tobacco, once exclusively sniffed by elderly women, was now on high demand by both younger women and girls in Zambia even if health experts warned that sunkho and other non-combusted tobacco products were highly addictive and could cause cancer of the head, neck, throat and oesophagus, as well as many serious oral and dental conditions (World Health Organization 2006:25). Scanty works on the Zambian academic landscape on sunkho was the motivation for this study. Well known studies conducted in Zambia on sunkho are two. One study was conducted by Kalubula, Shen and Khanam (2020) and the other study was done by Chimbala, Nabuzoka \& Paul (2020). In their academic article, Assessment of carcinogenic and toxic substances in 'insunkho' herb Kalubula et al. (2020) observed that sunkho was widely used in Zambia. The focus of Kalubula et al. (2020)'s study was to analyze carcinogenic and toxic substances in sunkho. Chimbala et al. (2020) investigated factors associated with usage of sunkho and the neurocognitive effects thereof. Due to lack of an in-depth study on the subject, it was unclear where users sourced sunkho, unclear how users consumed sunkho and unclear whether users were aware about health-related effects of sunkho despite what seemed to be an eccentric rush for sunkho especially among younger women and girls.

This study was conducted in Petauke and Chipata DistrictsZambia. Petauke and Chipata districts are located in the Eastern part of Zambia. Petauke district derives its name from a stream called Petauke while Chipata simply means the gate in local nyanja language because it borders with Malawi. Petauke district had a population of 249,919 people as at $31^{\text {st }}$ December, 2019 (Petauke District Health Office, during Provincial Integrated Meeting on $25^{\text {th }}$ September 2019) while Chipata had 281,020 people (Chipata District Health Office during Provincial Integrated Meeting on $25^{\text {th }}$ September, 2019). The two districts form the two surrogates of Eastern Province. The population of females in both districts excels that of males.

\section{Research Questions}

What is sunkho and where is it sourced?

How is sunkho consumed?

Why the explosive rush for sunkho among younger women?

\section{METHODOLOGY}

The study used an explorative design with a qualitative approach. It was conducted between March and June, 2021. Participants were drawn from the Central Business District and rural parts of Chipata and Petauke districts- Zambia. The study used the single-interview-per-participant data collection method. Creswell (1998) suggests the range of 20-30 respondents to be sufficient for an interview-study. This study used 25 participants broken into 6 males (2users and 4 non users) and 19 females (10 users and 9 non-users). Table 1. outlines participant distribution. All the 25 participants voluntarily agreed to participate in the study. User participants were sampled through snowball. The researchers were introduced to two female users who assisted to link them to other users. Interviews were conducted individually at different points. Assurance was made to participants that the 
exercise was meant to uncover social issues surrounding sunkho for learning purposes only. When the purpose of the study was carefully explained, participants voluntarily accepted to participate. To ensure study credibility and dependability, participants were sourced from both urban and rural areas. They included males and females of varying age ranges between 18 to 65years. Anonymity and confidentiality were assured as participants' names and their residential addresses were not recorded anywhere. Interviews were conducted in an atmosphere of informality for participants to feel free to share their perspectives. Each interview lasted 60 minutes. Refreshments were provided at the end of each interview for hydration only.

\section{Theory}

The study was guided by the Social Exchange Theory. This Sociological theory is attributed to George Homans (Redmond, 2015). Sociologist George Homans theorized that in all social interactions, basic economic principles revolving around rewards and costs are ever at play (Redmond, 2015). Individuals' decisions to engage in an interaction process are based on the use of a subjective cost benefit analysis and the comparison of alternatives'(Nunkoo 2015: 588 596). Underlying the Social Exchange Theory is the principle that people 'behave in ways to increase positively valued resources and decrease negatively valued resources' (Mitchell et al., 2012:100). Such behaviour results in the most profitable outcomes. As younger women and girls in Petauke and Chipata Districts- Zambia, interact among themselves, they exchange an array of social behaviours for which the use of sunkho is taken as a positive valued resource rewarding their social wellbeing.

\section{RESULTS}

\section{Question: What is sunkho and where is it sourced?}

The purpose of this question was to gain an understanding of what participants knew about sunkho and where users sourced it. From the interviews conducted, important themes emerged. These were the description of sunkho and where it was sourced. Participants explained that sunkho was fine ground tobacco made from a mixture of pounded dry tobacco leaves and filtrate of ash of burnt dry groundnut plants or vigamu (stripped cob) consumed by users through sniffing or dipping. Participants' responses were similar across the urban and rural spectrum. Nuances between two categories of participants lay in the ingredients of sunkho.

\section{Description of sunkho}

A male aged 65 years explained that, 'the use of sunkho is a practice with a long history for the very old in the village. Producers of sunkho use a mixture of pounded dry tobacco leaves with filtrate of burnt groundnut plants or bare corncob ash' (Male respondent - rural area). A female participant aged 59 years from the rural area added that in the village some sunkho-producers include dry, pounded roots or fruits of wild plants. 'Some sunkho producers in the village add sundried pounded roots of nthengele shrub and wembe fruits. Every woman in the village loves nthengele and wembe. These plants are magical. They work like burning charcoal heating up the brazier whenever a woman consumes them' (Female respondent, rural area). One of the urban female respondents reported that in urban areas, 'in recent times some local producers of sunkho make their product extremely dangerous by illegally adding marijuana, human urine, fertilizer or kachasu (an illegal home-made brew with alcohol content between $20 \%$ and $30 \%$ ) such that one teaspoon is sufficient to make three or four users feel drunk' (Female respondent, urban area). Over the colour of sunkho participants described it to have a shade ranging from light- brown to heavy darkbrown. 'Depending on the ingredients the colour of sunkho can be light-brown or to almost dark-brown' (Male respondent, urban area). A female from the rural area described the colour of sunkho as, 'coffee, coffee-like' (Female participant, rural area).

\section{Sources of sunkho}

Users from the rural area explained that they sourced homemade sunkho locally from villages while those from urban area in Petauke explained that they accessed sunkho from the towns outside Petauke district. A female user from Petauke urban area said, 'sunkho is a hot cake nowadays. Everyone is looking for sunkho. You can't find it anyhow. For me I buy enough from the market when I go to other towns outside Petauke' (Female participant, urban area). One user from the rural area in Chipata District was very succinct, 'whenever I crave sunkho I buy it locally. We have old people who know how to prepare sunkho in the village' (Female participant, rural area). One urban user from Chipata explained, 'I have agents who bring for me every month. The sunkho I use is not locally prepared. It comes from Tanzania. It rides tens of hundreds of miles before reaching here'(Female participant, urban area). A non-user female in Chipata reported that her friend also sourced her sunkho from Tanzania. 'My friend told me that there were two gentlemen from Tanzania who combed salons monthly with tins of sunkho selling a teaspoonful for five Kwacha (K5)'(Female urban area).

\section{How is sunkho consumed?}

This question was meant to gain an understanding of how sunkho was consumed. Participants explained that sunkho was consumed through a variety of ways. Users from the rural area mentioned about sniffing and dipping while urban users included placement of sunkho on or under the tongue and vaginal insertion.

\section{Modes of consumption}

A female user from the rural area in Petauke District reported that, 'I take a little pinch of sunkho with my left thumb and forefinger and put it on my right palm then sniff it' (Female participant, rural area). Another female user from the urban area in Chipata District explained how she and her friend 
consumed sunkho. 'My friend who uses sunkho places it on her tongue and then begins to suck it but for me I enjoy sunkho by placing it under my tongue so that I experience its effects faster just like those with heart problems do with their special little lozenge-like tablets'(Female respondent, urban area).

A male user from the urban area in Chipata District reported that he consumed sunkho by dipping it in the groove between the lower lip and the gum of the lower anterior teeth. 'I have been using sunkho for two years now. I don't sniff sunkho like many folks do. Instead I place sunkho between the lower lip and the lower gum. With pleasure I suck it to enjoy its flavour. I am able to differentiate tastes whether the sunkho is of high quality or poor quality by sucking,' (Male respondent, urban). He said with slurred speech while trying hard to hold the sunkho in place as it showed a bulge on the lower lip. Over vaginal insertion as a method of consuming sunkho, participants from the urban area were confident to shade brighter light. One male user from explained, 'you know .....eeh.. sunkho...assists women to keep tight, dry and hot.. hahaha' (Male respondent, urban area). When asked what he meant by keep tight, dry and hot the respondent simply said in words that were non-offensive but cryptic, 'eeh, we men want a frying pan that holds tight, is dry and red hot'(Male respondent, urban area). Female users from the urban area added a dimension, 'if sunkho helps your man to feel hot in bed then it's good to use it where he will taste its warmth,' (Female participant, urban area).

\section{Estimated percentage of younger women using sunkho}

When participants were asked to estimate the percentage of women aged between 18 and 35 years using sunkho, their responses varied from $40 \%$ to $60 \%$. 'For me I would say $40 \%$ ' (Male respondent, rural area). The other participant from the urban area had her own estimation. 'There are many women using sunkho nowadays. You go in markets, saloons even offices you see them sniffing sunkho so for me it's $60 \%$ ' (Female respondent, urban area). Another female user came out strongly, 'some of us are free spirited individuals. We speak out and hide not that sunkho is our saviour otherwise we wouldn't have had a man' (Female participant, urban area). One female When asked to choose between the single and the married who precisely used sunkho. 'It's 50-50 both the married and the single women use sunkho' (Female participant, rural area). A female participant from the urban area essayed her opinion along the viewpoint hailed by the latter participant. 'Sunkho has no marital boundaries. It has users among the singles as well as the married' (Female participant, urban area). From the males, one reported that, 'I usually see married women a lot sniff sunkho and sneeze around' (Male respondent, urban area). Another male participant amplified this observation, 'my sister in-law is married. She openly sniffs sunkho whenever she comes to our home (Male participant, rural area).
Question: Why the explosive rush for sunkho among younger women?

The question was designed to elicit information bordering on why suddenly and surprisingly, sunkho, which participants claimed to be the old women's preserve had become an ornament among younger women and girls reaching an unusual peak for its search and use. Participants explained that sunkho had always been the rightful dormitory for older women. Older women used it to cure boredom and persistent headaches. Five themes emerged from the interviews: ancient use of sunkho, explosive origins for widespread use of sunkho, sunkho was said to be a thermal generating agent that assisted the female body to get warmer and made the vagina hotter and tighter for the man's explosive sexual pleasure. Sunkho was also reported to increase CD4 Count for HIV Positive patients and that it was a trusted preventive measure against common cold including COVID-19.

\section{Ancient uses of sunkho}

'Sunkho has always been an exclusive portion for old women and to a lesser extent old men for treating boredom and headaches. Other engrossing uses included treatment of toothache by putting sunkho in the cavity of a painful tooth. But nowadays even females as young as 18 years are using sunkho' (Female respondent, urban area). A male respondent from the rural area aged 65 years dug a new well of information. In his response he stated that during olden days in the village, a couple with a new born baby was given sunkho for sniffing at intervals to enable them keep awake the entire night. 'When I was a boy, sunkho would only be used by very old women. Sunkho could only leave the bossom of the aged when there was a newly born baby. Parents to the neonate were told to sniff sunkho for the purpose of remaining awake so they could take care of their little one the entire night'(Male respondent, rural area). Over the subject of achieving insomnia, a woman aged 34 years said something interesting. She explained that in ancient days sunkho could only be used by younger women when they played the role of a bedsidder to enable them watch over their sick in the night without sleeping. 'Years ago my mother fell very ill and was admitted in the hospital. To ensure I remained awake during the night I could sniff sunkho. It helped me scatter the drowsy feeling of wanting to sleep' (Female participant). An aged female participant-a former Traditional Birth Attendant, gave an interesting response. She reported that sunkho was used as a traditionally trusted expellant of retained products of conception during the midwifery of yester years, 'a nyamwino kale- Traditional Birth Attendants in old-times used sunkho to assist a mother expel retained products of conception through sneezing after sniffing. The moment the mother sneezed once or again and again the retained products would be expelled out root and branch' (Female respondent, rural area). 


\section{Reasons for mass sprint for sunkho among younger females}

Participants cited a number of reasons why younger females were engaged in some crazy rush for sunkho. The reasons included fashionable lifestyle, alienation and loneliness, body temperature elevation, and desire for vaginal tightness. The study begins with tracing the origin of mass race for sunkho in rural areas and then proceeds with reasons for general outburst in interest for sunkho among younger females in both rural and urban areas.

\section{Origin of sunkho explosion in rural areas}

Participants from the rural area explained that the social behaviour to use sunkho among younger females was a foreign social behaviour brought by urban women. 'We didn't have such behaviour in the village. It is an urban export to the village. Urban women coming to the village to buy gaga, maize, groundnuts and soya beans sniff sunkho and spread word directly or indirectly that sunkho is a miracle mix that changes a woman's social landscape from being a stigmatized frigid and watery female to a hot and dry queen whom many men envy to sleep with,' (Female respondent, rural area). A male respondent from an urban area supported the latter view in the following terms, "there is always a wave of social influence beating upon communities whether urban or rural. Yes, change always begins from urban areas but it ripples out to rural areas. Women's revolutionary use of sunkho began with urban women' (Male respondent, urban area).

\section{Fashion}

A female respondent reported that it was a natural fit for both women and girls to respond when the fashion wave blew. A younger woman who resisted going along with the fashion was derided, lost friends or worse her man. 'It's fashionable nowadays to see women or girls use sunkho. Those who don't sniff or suck sunkho are looked at by fellow women as old fashioned and completely stranded I mean they are without a man or friends. Period' (Female respondent, urban). A male participant from the rural area gave a contrary view. 'Nowadays, marriage is a hot cake among females. Some females will do whatever it takes even to use sunkho to constrain a man and make him happy whether in a legitimate or illegitimate relationship' (Male respondent, rural area). A female user from the urban area was so direct in her response, 'nowadays, if a woman will not do her own part to attract or hold her man then she should forget'(Female participant, urban area). Asked what she meant she stated with a direct face, 'men are for sharing. You snooze you lose'(Female participant, urban area). Another female from the urban area elaborated more on the issue of sunkho and fashion. 'If a woman does not sniff or dip sunkho these days then she will utterly feel out of place in salons, kitchen parties and other women specific gatherings' (Female participant, urban area).

Alienation, loneliness, stress and depression

Another female participant from the urban area drew the study to an interesting area. In her contribution she said that society had changed a lot. Supportive social net works crucial for fighting alienation and loneliness had broken down following westernization, , 'our society is no longer as predictable and cohesive as it was decades past. Women are more lonely these days. Some can't find something to do to earn a living or they are simply disappointed in a relationship or just things aren't working out the way they wished. All these factors drive them to look for some relief in sunkho to deal with stress and depression' (Female respondent, urban area).

Sunkho was said to be a thermal generating agent for women and girls

Participants reported that sunkho was widely believed to elevate a woman's temperature from cold to burning warm. A female participant from a rural area observed, 'users say it warms up a woman's body' ( Female respondent rural area). A male respondent from another rural area said, 'there are truly medicinal plants in the village which if added to sunkho a woman's body really gets hot as if she has malaria (Male respondent, rural area). A female respondent from urban area said in her few words, 'Sunkho is magical. It adds respect and dignity to a woman' (Female respondent, urban area). When asked how sunkho raises the user's body temperature, the latter participant said 'I may not know how but I think I can tell you su..' she said without even completing the word sunkho, 'is just what we need. It's working for me and it's working for my friends. Nothing does better than sunkho in hoisting the temperature. No wonder everyone is rushing for the neglected gold whether married or single'(Female respondent, urban area). The male respondent from the rural area who earlier talked about the coveted medicinal plants with properties to volley up a woman's temperature reemphasized, 'when sunkho is mixed with the right herbs it does wonders to women's temperature,' Male respondent, rural area). A non-user female from the urban area said, 'my friends who sniff sunkho boast a lot that they have what a man wants- red-hot bodies' (Female participant).

\section{Sunkho was said to be a vaginal drying and constricting agent}

Two elderly males explained that while females may follow their tradition, males played a huge role in influencing the social course of actions taken by females with regard to their sexuality. 'When a man has sex with a female whose womanhood feels hot, dry and tight the female automatically becomes a darling to the man whether single or married' (Male respondent, urban area). The male respondent continued, 'the female who gets hooked to a dude because she is hot is envied by her friends' (Male participant). A female participant from the urban area in a straightforward manner explained that women contended with social forces greater than themselves, 'women are driven to use sunkho purely because that is what society wants. That is what men want. The man wants a woman who is hot and is small down here,' she said while putting a sweeping gesture from her abdomen downwards. 'If sunkho intersects both then a woman will use it to keep her marriage or make a crush on a man' (Female 
participant, urban area). The other female participant under the urban category explained that men loved a tight vagina. It was the sole reason why some men defiled minors in search of a tight vagina. 'Do you know why some men are serving long jail sentences for defilement? It's because they crave for a tight vagina. So if men want a tight vagina then his woman should use sunkho to ensure her vagina is dry, hot and ring tight to compel him to stay otherwise other women will give it to him or he will pounce on a minor and get imprisoned'(Female participant, urban area). A non user female from urban area narrated that users consume sunkho when they had an appointment for sex with a man. 'If she knows she has an appointment with a man that afternoon she sniffs, dips or inserts sunkho in the vagina as part of preparation to get hot and tight for his sexual bliss' (Female participant urban area). Another female non- user from urban area added, 'they only use sunkho when they know they are meeting a man hours before he pulls his trigger. What she wants is to share a bed when her entire body including the vagina is steamy hot. Don't make me laugh ha! Ha! Ha!'(Female participant, urban area).

\section{Claim sunkho increases CD4 Count in HIV Positive patients}

'A lot of young females on Anteretroviral drugs use sunkho. When you ask them they claim that sunkho boosts their CD4 count. When asked whether that was true all of the participants including those from the rural area utterly refused. 'It's the strangest lie. Only ARVs when taken at correct times consistently with good nutrition and positive living can assist to boost a patient's CD4 Count' (Male respondent, urban area). A female from rural area also said, 'they are just destroying themselves' (Female respondent, rural area). Even users of sunkho refused the claim but admitted that some of their friends hooked on sunkho consumed it daily for the sheer belief that their CD4 Count would spike.

Claim Sunkho was an African preventive measure against common cold and COVID-19

Participants gave interesting and shocking foot notes about sunkho in relation to the common cold and COVID 19. They reported that women who used sunkho claimed that they were not in danger of acquiring the common cold not even COVID19 because sunkho had what it took to fight the common cold virus including Sars-Cov2. 'Users claim that sunkho is a real wall of Jericho against flu even Covid-19' (Male respondent, urban area). A female respondent added, 'women claim that the tingling sensation and the brutal sneezing arising from sniffing sunkho was sufficient to blow COVID virus out of the body'(Female participant, urban area). One female urbanite who said she was going out to have a drink of alcohol that night explained, 'look COVID-19 is after the rich and the famous. Drunkards and prostitutes are intact. You know why it's because all these categories of people use sunkho. Here I am alive and free from COVID-19 because I sniff sunkho three times a day for prevention' (Female participant, urban area). When other participants were asked whether the prevailing information about sunkho in relation to COVID-19 prevention was true, all the participants refused.

'It's an outrageous claim. It's not true at all. No wonder cases of COVID-19 are rising in Eastern Province because of such claims that give false security to people' (Male respondent, urban area). A female participant also from the urban area said, 'users are using every excuse to legitimize their use of sunkho and also to draw disciples after them' (Female respondent, urban area).

\section{What do you know about the health-related effects of sunkho?}

This question was meant to find out the extent to which participants were aware about the health-related effects of sunkho. Nearly $90 \%$ of participants in the study claimed that sunkho was safe for use. It did not pose any danger to health. They claimed they were not aware of any health risks. They substantiated their claim by stating that tobacco's healthrelated risks were associated to tobacco smoking only. One male user claimed that sunkho was natural and therefore, safe for use. 'Sunkho is natural. It's safe'(Male user, urban area). A female user said, 'sunkho ili ce- it's ok'(Female participant, urban area). Another female user from the rural area said, 'if our ancestors used sunkho it means sunkho is safe' (Female participant, rural area). When asked whether health workers sensitize communities on health-related effects of sunkho, except for one all the participants denied. The participant who accepted seeing health workers sensitizing her community on health-related effects of sunkho reported that she would still not quit. She explained that she had heard from health workers that sunkho was as bad as smoking but was encouraged to continue with the social behaviour because the same health workers would be seen privately sniffing sunkho. 'When the preacher tells you one thing yet does the opposite it's confusing isn't it? If a health worker while in uniform tells you sunkho is bad for health, later the same day you see her sniffing sunkho tell me do you believe her words or actions?' (Female participant, urban area). A male user explained that health workers sensitized communities on tobacco smoking only and not on the use of sunkho. 'They sensitize us against tobacco smoking but over the use of sunkho I have never seen them lift their tongues against sunkho' (Female participant, rural area). One female user from the urban area said something clearly outside what others had shared, 'I hear sunkho is bad because they say it causes loss of teeth if one dips between the lower lip and gum and that it causes cancer'(Female participant, urban area). Asked whether she would cease the habit following the information she had, the participant said, 'science is good but when you have an appointment with a dude who has promised to buy you a car what do you do? Let me tell you. You pick sunkho and prepare yourself so that your man is happy else he won't come back he! he! he! he!'(Female participant, urban area). Asked about addiction to sunkho the user simply said, 'if addiction to sunkho enables a female to keep her man then what can you say about sunkho?' (Female participant, urban area). 


\section{DISCUSSION}

Sunkho - a mixture of fine ground tobacco and the traditional alkaline filtrate of burnt bare corn cob or ground nut plants that once characterized the landscape of the very old in the rural, was now being hunted restlessly by younger females. This in-depth study set out to find out where users sourced sunkho, how sunkho was consumed, why there was a mass sprint for sunkho among younger women and whether users were aware about health-related effects of sunkho. This was a novel academic inquiry as the National Cancer Institute and Centers for Disease Control and Prevention (National Cancer Institute and Centers for Disease Control and Prevention, 2014) observed that smokeless products present a complex and widespread challenge to public health but has so far received limited attention from researchers and policymaker (National Cancer Institute and Centers for Disease Control and Prevention 2014:5). The study was conducted between March and June, 2021 among rural and urban populations of Petauke and Chipata districts- Zambia. In this study, participants described sunkho as fine ground tobacco made from a mixture of pounded dry tobacco leaves and filtrate from ash of burnt dry groundnut plants or vigamu (stripped cob) sniffed or placed in the mouth for sucking.

This definition is similar to the scholarly description by The Physicians for a Smoke-Free Canada (2010) whose definition of sunkho states -finely ground tobacco that can be dry or moist for which dry snuff often comes in powder form and is inhaled through the nose while moist snuff is placed between the lip and gum and does not need to be chewed (Physicians for a Smoke-Free Canada, 2010). Kalubula et al.,(2020) also define sunkho as a mixture of powdered tobacco, ash, soda and other ingredients. The study found that users consumed sunkho through sniffing, dipping, and vaginal insertion. Users in the rural area reported of sniffing and dipping as known methods for consuming sunkho. Urban users reported of vaginal insertion and placement on or under the tongue in addition to the two conservative methods mentioned in the former. Findings of this study are similar to the study by Chimbala et al., (2020) titled Factors Associated with Snuff Usage and its Neurocognitive Effects among Women in Ndola Urban, Zambia in which participants reported of sniffing, dipping including vaginal insertion as the existing methods of consuming sunkho. This study also found that younger females rushed for sunkho for body temperature elevation and vaginal tightening for the man's sexual pleasure. These findings tally with the study findings of Gafos et al., (2010). In their study among the Zulu men and women of Kwazulu Natal-South Africa, Gafos et al., (2010) found that both men and women expressed greater sexual satisfaction and pleasure following vaginal insertions. Participants explained that their sexual experience on a dry, hot and tight vagina was thrilling and memorable. Unlike their study which investigated sexual experience following administration of microbicide gels as intravaginal insertion agents, this study focused on the use of sunkho as the social phenom of interest.
With regard to awareness on health-related effects of sunkho, this study found that $90 \%$ of the participants were not aware. They based their opinion that sunkho was safe because it was natural and homemade. Other participants argued that the fact that sunkho was like a cultural relic as such it was safe for use. These finding support the findings of Mohan et al. (2018) in Mackay and Crofton (1996) who indicated that lack of awareness of the potential problems and definite health hazards associated with tobacco consumption and the tactics of the tobacco industry and vendors to target the vulnerable population, the women and the youth, bolster the increased tobacco consumption in developing countries (Mohan et al., 2018 in Mackay \& Crofton, 1996). Other participants reported that while health workers had done exceptionally well to sensitize communities on HIV AIDS, COVID-19 and tobacco smoking they had not sensitized communities on sunkho. Over creation of awareness to communities on sunkho and other smokeless products the World Health Organization observes that health professionals have a key role in tobacco control but have not been effectively brought into this area (WHO, 2011).

\section{CONCLUSION}

Sunkho also known as snuff is a finely ground dried tobacco leaves with one or more ingredients inhaled through the nose in powder form or dipped in the mouth as a moist mixture. In most cultures, sunkho was essentially for the elderly. Some younger females in Zambia have hurled down the cultural practice favouring the aged over the use of sunkho. This study explored the reasons for the unusual social behaviour and investigated the level of awareness on sunkho's associated health risks. This study found that younger women dashed for sunkho to elevate their body temperature from ordinary-warm to unusual-warmer and for vaginal tightening so that a man enjoys memorable and satisfactory sexual pleasure. Some users consumed sunkho based on the underlying belief that sunkho helps to boost CD4 Count in HIV positive patients. This study also found that other users consumed sunkho under the belief that it helped them not acquire COVID-19 infection.

\section{RECOMMENDATIONS}

Since this study found low levels of awareness on healthassociated risks of sunkho and other smokeless tobacco products, the study recommends that health workers conduct aggressive community sensitization campaigns on the effects of sunkho and other smokeless tobacco products on health. The study further recommends that institutions offering health-related training programmes to include the use of Smokeless tobacco in their curriculum as a new threat to the emergence of malignancies of unknown origin. Ministry of Education to take a critical step in creating awareness to all pupils and students on the dangers of using sunkho and other smokeless tobacco products. The Drug Enforcement Commission to conduct regular random analysis of sunkho for other dangerous possible ingredients such as marijuana, cocaine, heroin etc. 


\section{Limitations of the study}

The study used a small sample from two districts therefore; the findings cannot be generalized to the larger population. Participants who volunteered to participate in this study were from the lower class. A further study has to be conducted with participants from the middle and upper class.

\section{ACKNOWLEDGEMENT}

The authors would like to thank all the participants for their time and contributions to the study.

Table1.Demographic characteristics of participants

\begin{tabular}{|c|c|c|c|c|}
\hline Variables & \multicolumn{2}{|c|}{$\begin{array}{c}\text { Participants from Chipata } \\
\text { District }\end{array}$} & \multicolumn{2}{|c|}{$\begin{array}{c}\text { Participants from Petauke } \\
\text { District }\end{array}$} \\
\hline \multirow{2}{*}{ Gender } & Male & Female & Male & Female \\
\hline & $4(16 \%)$ & $13(52 \%)$ & $2(8 \%)$ & $6(24 \%)$ \\
\hline $\begin{array}{l}\text { Age in } \\
\text { years }\end{array}$ & $\begin{array}{c}18-22 \\
0 \\
23-27 \\
1 \\
28-32 \\
2 \\
33-37 \\
0 \\
38-42 \\
0 \\
43 \text { and above } \\
1\end{array}$ & $\begin{array}{c}18-22 \\
2 \\
23-27 \\
3 \\
28-32 \\
3 \\
33-37 \\
2 \\
38-42 \\
1 \\
43 \text { and } \\
\text { above } 2\end{array}$ & $\begin{array}{c}18-22 \\
0 \\
23-27 \\
1 \\
28-32 \\
1 \\
33-37 \\
0 \\
38-42 \\
0 \\
43 \text { and above } \\
0\end{array}$ & $\begin{array}{c}18-22 \\
2 \\
23-27 \\
2 \\
28-32 \\
1 \\
33-37 \\
0 \\
38-42 \\
0 \\
43 \text { and } \\
\text { above } 1\end{array}$ \\
\hline Rural & 1 & 4 & 1 & 2 \\
\hline Urban & 3 & 10 & 1 & 4 \\
\hline $\begin{array}{c}\text { Sunkho } \\
\text { user }\end{array}$ & 1 & 7 & 1 & 3 \\
\hline $\begin{array}{c}\text { Sunkho } \\
\text { non- user }\end{array}$ & 3 & 6 & 1 & 3 \\
\hline
\end{tabular}

\section{REFERENCES}

[1] Bauman, K.E., Koch, G.G., Letz, G.M.(1989). Parent characteristics, perceived health risks, and smoke less tobacco use among white adolescent males. National Cancer Institute Monographs 8: 43-48

[2] Braun, V.(2005). In Search of (Better) Sexual Pleasure: Female Genital 'Cosmetic' Surgery. Sexualities vol. 8(4) 402-424 DOI: 10:1177/1363460705056625 accessed from www.researchgate.org on $1^{\text {st } J u l y, 2021 @ 20 h r s ~}$

[3] Centres for Disease Control and Prevention (2019). Smokeless Tobacco Product Use in the United States Fast Facts and Fact Sheet

https://www.cdc.gov/tobacco/data_statistics/fact_sheets/smokeless /use us/index.htm\#adult-national accessed on $2^{\text {nd }}$ July, 2021 at $10 \mathrm{hrs}$

[4] Chipata District Health Office in Provincial Integrated Meeting held on the $25^{\text {th }}$ September, 2019

[5] Chimbala, L. Nabuzoka, D., Paul, R.(2020). Factors Associated with Snuff Usage and its Neurocognitive Effects among Women in Ndola Urban, Zambia. Medical Journal of Zambia, Vol. 47 (1): 25 - 32 (2020)

[6] Das, S. (2018).Flavoured smokeless tobacco use in India and Bangladesh. Tob. Induc. Dis. 2018;16(Suppl 1):A786 https://doi.org/10.18332/tid/84338 accessed on the 15th of June, 2021 at $08 \mathrm{hrs}$

[7] European Union- Scientific Committe. (2008). Health Effects of Smokeless Tobacco Products. Brusssels
[8] Gafos, M. Mzimela, M. Sukazi, S. Pool, R., Montgomery, C., Elford, J.(2010). Intravaginal insertion in KwaZulu-Natal: sexual practices and preferences in the context of microbicide gel use. Culture, Health \& Sexuality vol. 12, (8), November 2010, 929-942

[9] Giovino,G.A. (2002). Epidemiology of tobacco use in the United States. Oncogene (2002) 21, 7326-7340

[10] Hassanin, A. A., Idris, A.M.(2017). Attribution of oral cancer in the Sudan to Toombak dipping. Translational Research in Oral Oncology Volume 2: 15https://doi.org/10.1177\%2F2057178X16685729

[11] Høstmark, M., Jensen, A., Otnes, B.(2017). Fewer people smoke, but more women use snuff.https://www.ssb.no/en accessed on the $11^{\text {th }}$ of July, 2021 at $12 \mathrm{hrs}$

[12] Kalubula, M. Shen, H. Khanam, T. (2020). Assessment of carcinogenic and toxic substances in 'insuko' herb. Toxicology Reports 7(2020) 468-474 www.elsevier.com/locate/toxrep.

[13] Leon, M.E., Lugo. E., Boffetta, P. Gilmore, A., Ross, H., Schu“ J., La Vecchia, C., Gallus, S.(2016). Smokeless tobacco use in Sweden and other 17 European countries. The European Journal of Public Health, Vol. 26, No. 5, 817-82

[14] Mohan, P., Lando, H.A., Panneer, S.(2018). Assessment of Tobacco Consumption and Control in India Indian Journal of Clinical Medicine Volume 9: 1-8. In Mackay J, Crofton, J.(1996). Tobacco and the developing world. Br Med Bull. 1996; 52:206221.

[15] Mcglyn, J.B.(2019). "Seduced By The Charms Of A Fashionable Box": Addiction And The Snuff Box In Early America https://cpb$\underline{\text { us- }}$

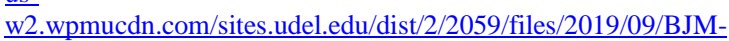
Snuff-PDF-form1.pdf Accessed on the 8th of July, 2021

[16] Mitchell, M. S., Cropanzana, R. S., \& Quisenberry, D. M. (2012). Social exchange theory, exchange resources, and interpersonal relationships: A modest resolution of theoretical difficulties. In K. Törnblom \& A. Kazemi (Eds.), Handbook of Social Resource Theory: Theoretical Extensions, Empirical Insights, and Social Applications, (pp. 99-118.) NY, NY: Springer.

[17] Mwitwa, M.(2018). Plying Bedroom Duties. Lusaka: Zambia Daily Mail

[18] National Cancer Institute and Centers for Disease Control and Prevention. Smokeless Tobacco and Public Health: A Global Perspective. Bethesda, MD: U.S. Department of Health and Human Services, Centers for Disease Control and Prevention and National Institutes of Health, National Cancer Institute. NIH Publication No. 14-7983; 2014.

[19] Ndinda, G. Uzodike, U.O., Chimbwete, C. Mgeyane, M.TM. (2011). Gendered Perceptions of Sexual Behaviours in Rural South Africa. International Journal of Family Medicine doi: $10.1155 / 2011 / 973706$

[20] Nunkoo, R. (2015). Toward a More Comprehensive Use of Social Exchange Theory to Study Residents' Attitudes to Tourism. 3rd Global Conference On Business, Economics, Management And Tourism, 26-28 November 2015, Rome, Italy. Procedia Economics and Finance 39 ( 2016 ) 588 - 596

[21] Pampel, F.C.(2008). Tobacco use in Sub-Saharan Africa:Estimated from the Demographic Health Surveys. Social Science \& Medicine, 66(8) 1772-1783. Available at: http:///ac.elscdn.com.ezproxy.ut.ac.za/S02779536545/1-S2.0S0277953607006545-MAIN.PDF?TID=72F00-9240-11E3-B93200000AAB0F26\&ACDNAT+1392029273 823ED1451912668FC 57DF8DF45A8945CACCESSED ON the $9^{\text {th }}$ of July, 2021 at 20hrs

[22] Petauke District Health Office in Provincial Integrated Meeting held on the $25^{\text {th }}$ September, 2019

[23] Physicians for a Smoke-Free Canada (PSFC). (2010). Smokeless tobacco: New trends for an old product. Ottawa. Retrieved Jan 13, 2012 from http://www.smokefree.ca/pdf 1/smokeless-2011b.pdf

[24] Redmond, Mark V., "Social Exchange Theory" (2015).English Technical Reports and White Papers. 5 http://lib.dr.iastate.edu/engl_reports/5?utm_source=lib.dr.iastate.e du\%2Fengl reports $\% 2 F 5 \& u t m$ medium $=P D F \& u t m$ campaign $=P$ DFCoverPages accessed on the $5^{\text {th }}$ of July, 2021 at $12 \mathrm{hrs}$ 
[25] Sand, L. Wallström, M. Hirsc, Jan-Michaél. (2014). Smokeless Tobacco, Viruses and Oral Cancer. OHDM - Vol. 13 - No. 2 June, 201

[26] Sieminska, A., Jassem, E.(2014). The nany faces of Tobacco use among women. Med Sci Monit. 2014 Jan 30; 20:15362.doi:10.12659/MSM.88976.pmid:24487778;pmcid:pmc3915001

[27] Sinha, D.N., Gupta, P.C., Kumar,A., Bhartiya, D., Agarwal, N., Sharma, S., Singh, H., Parascandola, M., Mehrotra, R.(2018). The poorest of poor suffer the greatest burden from smokeless tobacco use: a study from 140 countries. Nicotine Tob. Res. 2018; 20: 1529-32

[28] World Health Organization(2006). Tobacco: deadly in any form or disguise

https://www.who.int/tobacco/communications/events/wntd/2006/R eport v8 4May06.pdf accessed on the 11th of July, 2021 at 12hrs
[29] WHO (2011). WHO Report on Global Tobacco Epidemic, 2011. Geneva, Switzerland: The EMPOWER Package.

[30] World Health Organization(2017).Types of Tobacco Use https://www.afro.who.int/sites/default/files/201709/Chapter\%201. \%20Types\%20of\%20tobacco\%20use_1.pdf

[31] World

Health Organization.(2017).HistoryofTobaccohttps://www.afro.who.int/si tes/default/files/2017-

09/Chapter\%2032.\%20The\%20history\%20of\%20tobacco.pdf

[32] Virginia, B., Kitzinger, C.( 2001).The perfectible vagina: size matters. Culture, Health \& Sexuality, 2001, Vol. 3, NO. 3, $263 \pm 277$

[33] 2018 Tanzania Global Adult Tobacco Survey Country Report (2020). Dar-es- Salaam: National Bureau of Statistics 